\title{
The Effect of Combination Electrospun and Meltblown Filtration Materials on Their Filtration Efficiency
}

\author{
Dusan Kimmer ${ }^{1, \text { a) }}$, Ivo Vincent ${ }^{1, b)}$, Wannes Sambaer ${ }^{2, c)}$, \\ Martin Zatloukal $^{2,3, \text { d) }}$ and Jakub Ondracek ${ }^{4, \text { e) }}$ \\ ${ }^{1}$ SPUR a.s., trida Tomase Bati 299, Louky, 76302 Zlin, Czech Republic \\ ${ }^{2}$ Polymer Centre, Faculty of Technology, Tomas Bata University in Zlin, \\ nám. T. G. Masaryka 275, 76272 Zlin, Czech Republic \\ ${ }^{3}$ Centre of Polymer Systems, University Institute, Tomas Bata University in Zlin, \\ Nad Ovcirnou 3685, 76001 Zlin, Czech Republic \\ ${ }^{4}$ Institute of Chemical Process Fundamentals of the CAS, v. v. i., \\ Rozvojová 135/1, 16502 Praha 6, Czech Republic \\ ${ }^{\text {a)}}$ Corresponding author: dusan.kimmer@spur.cz \\ b)ivo.vincent@spur.cz \\ ${ }^{c)}$ wannessambaer@gmail.com \\ d) mzatloukal@ft.utb.cz \\ e)ondracek@icpf.cas.cz
}

\begin{abstract}
Filtration materials prepared by combination of electrospun nanofibers and meltblown microfibers (both fixed on polypropylene spunbond supports) were characterized from the point of view of their filtration efficiency in ultrafine particles separation. Compared are electrospun and meltblown structures and their combinations characterized by means of digital image analysis properly. Layer of electrospun nanofibers in MB air filtration materials can ensure improvement of filtration efficiencies for ultrafine particles separation.
\end{abstract}

\section{INTRODUCTION}

Air filtration materials for the elimination of ultrafine particles by microfiltration and ultrafiltration are generally based on melt blown (MB) microfibers or electrospun (ES) nanofibers on spun bond (SB) supports [1-7]. Sole MB filtration materials exhibit very good filtration efficiencies for separation of $\mathrm{NaCl}$ particles in accordance with EN 143 and EN 149 but separation of paraffin oils is rather poor. To eliminate this shortcomings the suitable combination of MB materials with ES nanostructures (both fixed on polypropylene (PP) SB supports) can be used.

\section{EXPERIMENTAL}

\section{Materials}

A modified polyvinylidene fluoride (PVDF) solution in dimethyl formamide for spinning process in electrostatic field was prepared with concentration $13 \%$ by mass, viscosity of $1.3 \mathrm{~Pa} . \mathrm{s}$ and its conductivity was increased to 150 $\mu \mathrm{S} . \mathrm{cm}^{-1}$ by addition of borax and citric acid.

Commercial product Ecotextil FNAE 1809 was used as the polypropylene based MB microfiber material with basis weight 25 g.m $\mathrm{m}^{-2}$ layered on PP SB collecting support with basis weight 17 g.m $\mathrm{m}^{-2}$. 


\section{Filter Sample Preparation by Electrospinning Process}

Nanofibre layers were prepared from PVDF solutions in DMF with a commercially available SpinLine machine (SPUR a.s., Zlín, Czech Republic, http://www.spur-nanotechnologies.cz/) equipped with a patented rotating electrode with cotton cords spinning elements (CZ305037; PCT/CZ2010/000042) or nanofibres forming jets. The experimental conditions were as follows: relative humidity: $29 \%$, temperature: $23^{\circ} \mathrm{C}$, electric voltage applied to PU solution: $115 \mathrm{kV}$, distance between electrodes: $260 \mathrm{~mm}$, speed of supporting textile collecting nanofibres: $0.8 \mathrm{~m} \cdot \mathrm{min}^{-1}$. Nanostructures in weight $0.2 \mathrm{~g} \cdot \mathrm{m}^{-2}$ were collected on PP SB nonwoven textiles with basis weight 30 g.m. $\mathrm{m}^{-2}$.

\section{ES and MB Filter Sample Characterization}

Nanofibre-based filter prepared by the electrospinning process was characterized by a scanning electron microscope (SEM, Vega 3, Tescan, Czech Republic). In some cases the SEM images obtained were consequently used to determine fibre diameter distribution, pore size distribution, build up representative 3D filter models and filtration efficiency by using the recently developed UTB soft Filtration v1.0.1 simulation software utilizing digital image analysis technique and filtration model described in [8-10].

\section{Filtration Efficiency}

The filtration efficiency in the ultrafine particle size range was determined as a function of particle diameter. A 1 g. $1^{-1}$ ammonium sulphate solution was nebulised (AGK 2000, PALAS, Germany), a monodisperse size fraction was selected using an Electrostatic Classifier (Goliath, ICPF AS CR, including Vienna type DMA), and particle concentration upstream and downstream the filter (face velocities $5.9 \mathrm{~cm} . \mathrm{s}^{-1}$ and $48.3 \mathrm{~cm} . \mathrm{s}^{-1}$ ) was recorded by two condensation particle counters (both UCPC 3025 A, TSI, USA). The filtration efficiency was determined at nine mobility diameter fractions: 20, 35, 50, 70, 100, 140, 200, 280 and $400 \mathrm{~nm}$. Each filtration efficiency values and its pressure drops were measured repeatedly at steady state of experimental lay out. The Most Penetrating Particle Size (MPPS) for all samples were evaluated and used for material characterization.

\section{RESULTS AND DISCUSSION}

The prediction of filtration efficiencies and evaluation of effect of combination PP MB and PVDF ES materials on ultrafine particles capture are the main aims of our interest in this study.

In the Figs. 1 and 2 the SEM images and 3D filter models of initial MB and ES filtration structures are summed up.

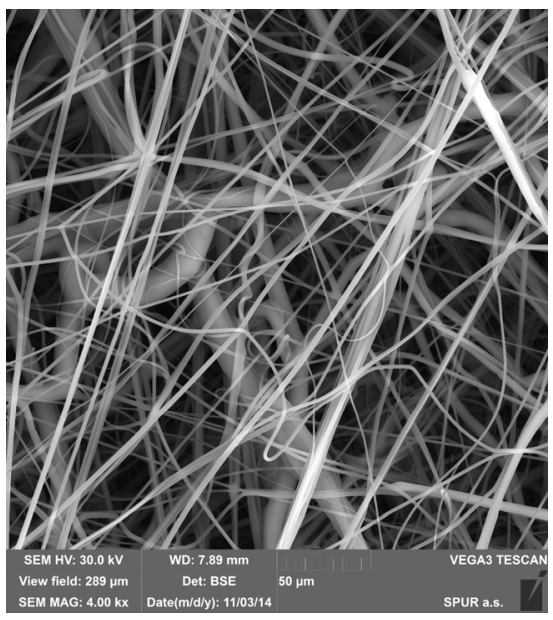

a)

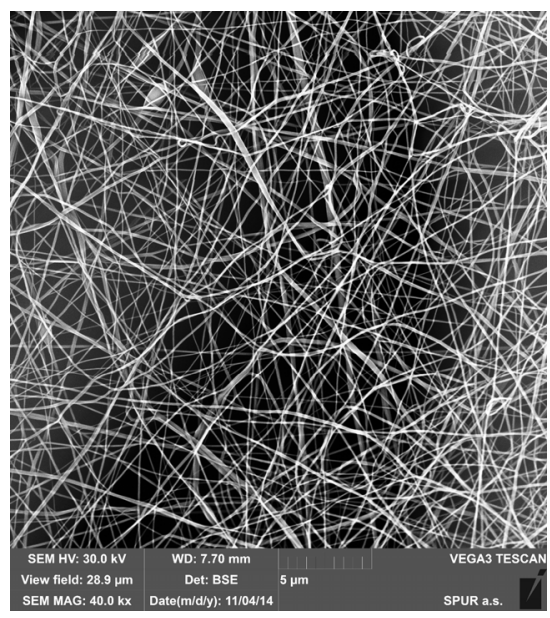

b)

FIGURE 1. SEM picture of (a) MB (magnification 4000×) and (b) ES (magnification 40000×) material. 


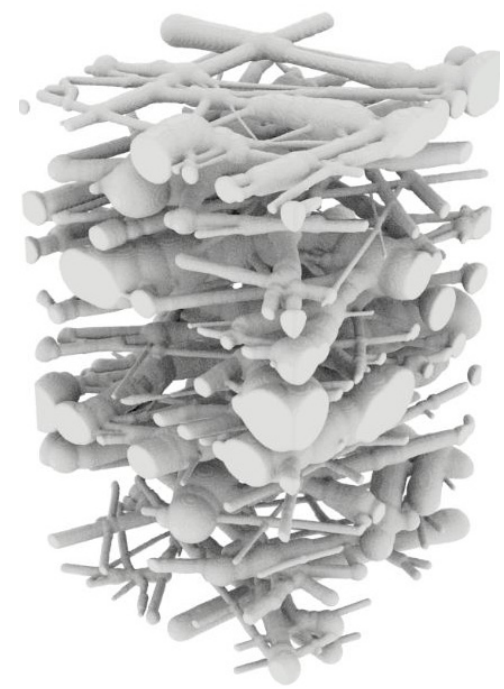

a)

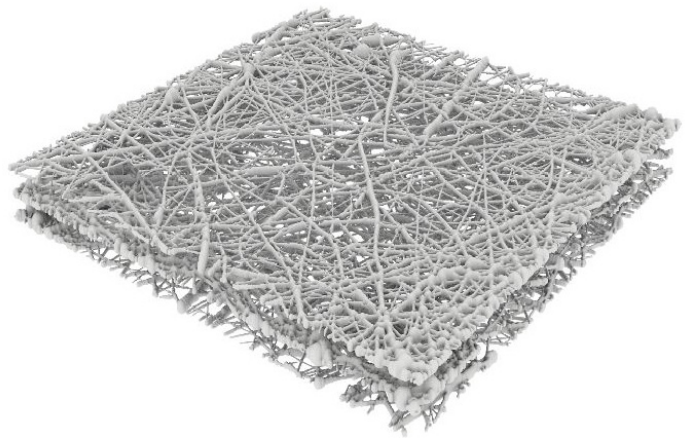

b)

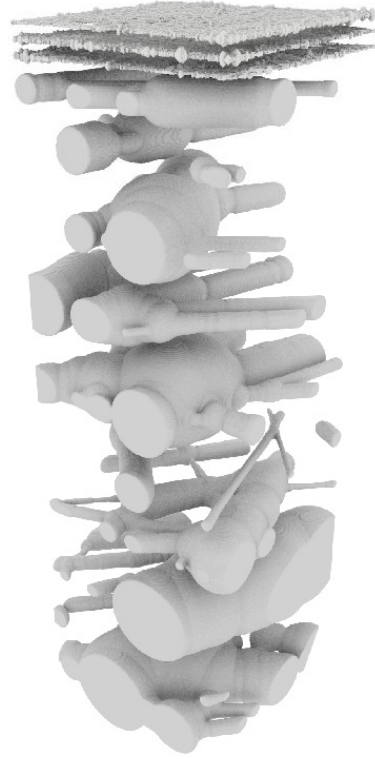

c)

FIGURE 2. (a) MB filter model (25 g.m $\left.{ }^{-2}\right)$, (b) ES filter model $\left(0.2 \mathrm{~g} . \mathrm{m}^{-2}\right)$, (c) Full ES+MB filter model.

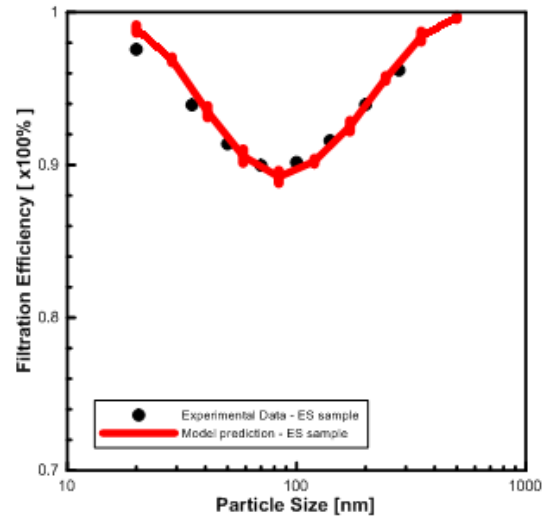

a)

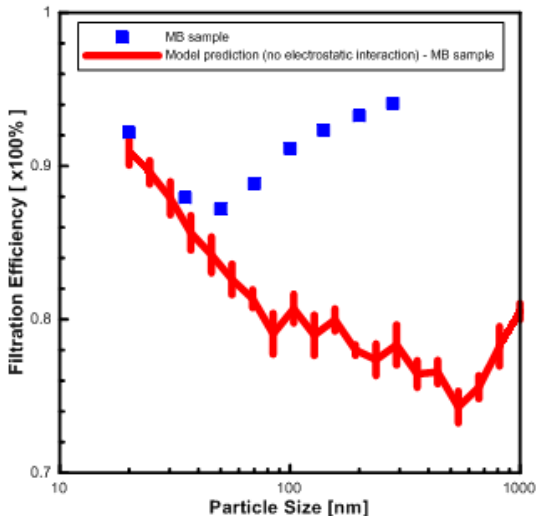

b)

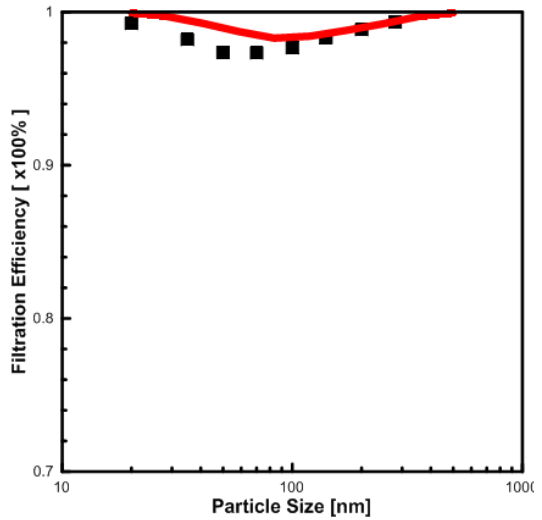

c)

FIGURE 3. Model prediction (line) vs. the experimental data (points) for (a) the ES sample, (b) the MB sample (no electrostatic interactions) and (c) the ES+MB material combination (MB prediction without any electrostatic interactions).

Model prediction and experimentally measured values for elimination of ammonium sulphate ultrafine particles (Fig. 3a-c) by means of ES nanostructure are in excellent compliance (Fig. 3a). The prediction of filtration properties for $\mathrm{MB}$ materials is rather complicated, the treatment of microfibers by means of electrostatic charge can be the reason. In Fig. $3 \mathrm{~b}$ we compare model prediction for the MB sample without any electrostatic interaction with experimental data for commercial charged MB filtration material Ecotextil FNAE 1809 at face velocity $5.9 \mathrm{~cm} . \mathrm{s}^{-1}$. In accordance with the theoretical assumption the MPPS for MB structure without any electrostatic interaction is shifted to higher values. Nevertheless ultrafine particles separation properties of charged MB materials are very good.

The best imagine about morphology of nanostructured and microstructured filtration materials we can create from the fiber and pore size distribution charts depicted on Figs. 4 and 5. 


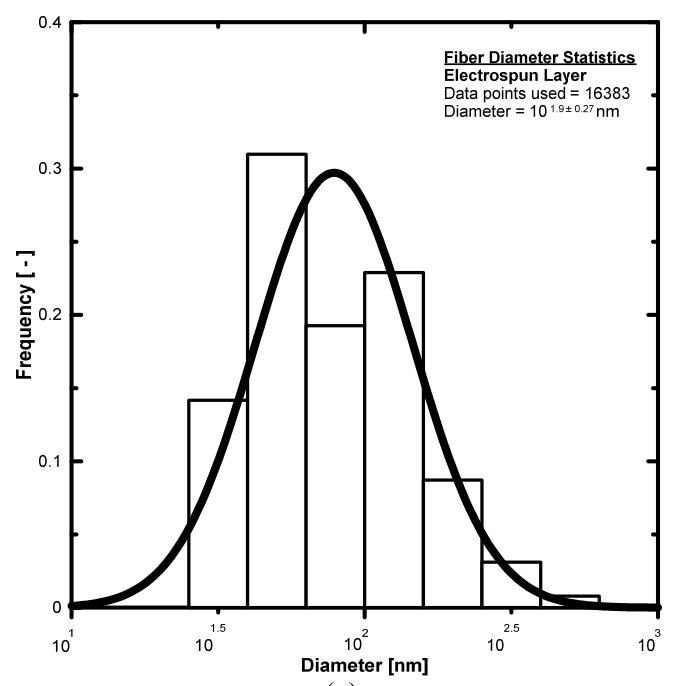

(a)

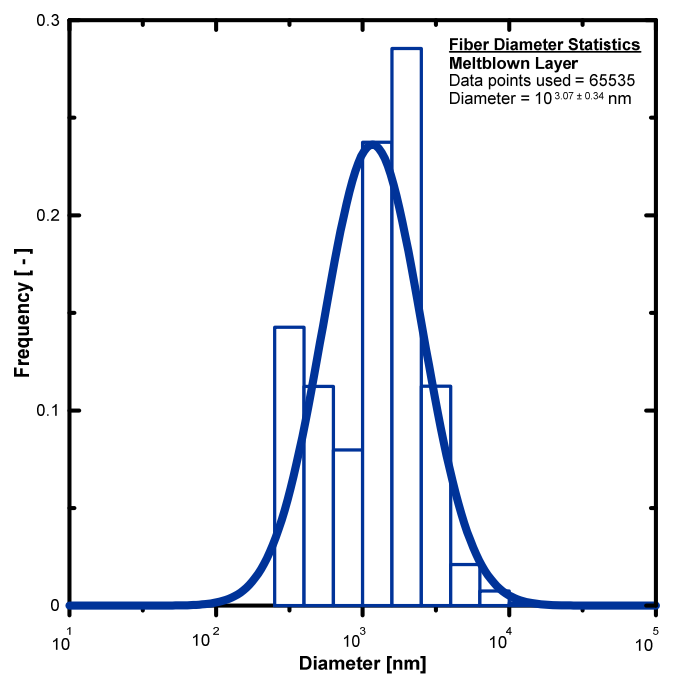

(b)

FIGURE 4. Fiber diameter of (a) ES and (b) MB material.

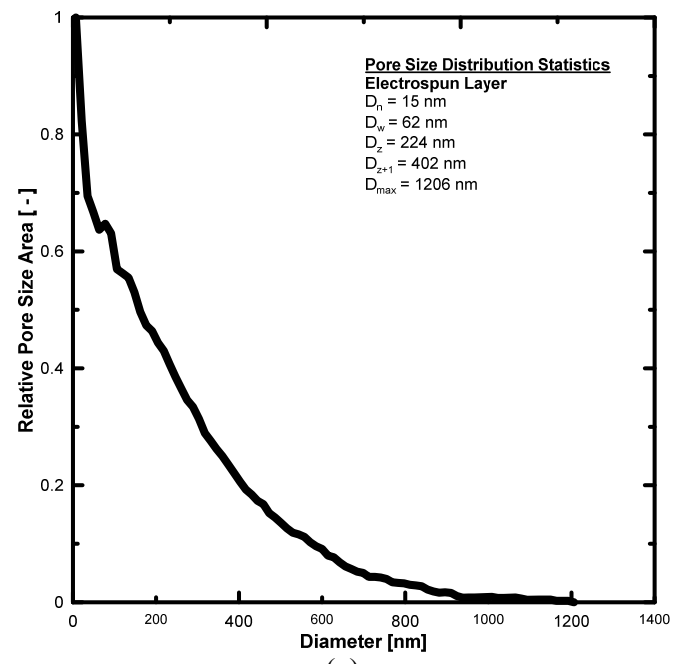

(a)

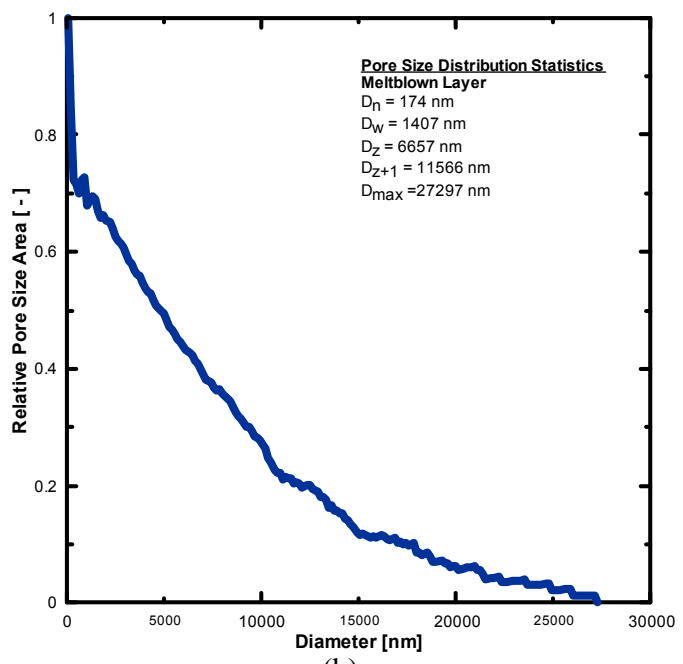

(b)

FIGURE 5. Pore size distribution of (a) ES and (b) MB material.

Results of filtration efficiency experimental measurements for ES, MB and ES+MB filtration materials at face velocity $48.3 \mathrm{~cm} \cdot \mathrm{s}^{-1}$ are represented on Fig 6 . ES nanostructure (basis weight $=0.2 \mathrm{~g} \cdot \mathrm{m}^{-2}$ ) exhibit higher filtration efficiency than $\mathrm{MB}$ microstructure (basis weight $=25 \mathrm{~g} \cdot \mathrm{m}^{-2}$ ) and quantity of polymeric mass used is more than 100 times lower. 


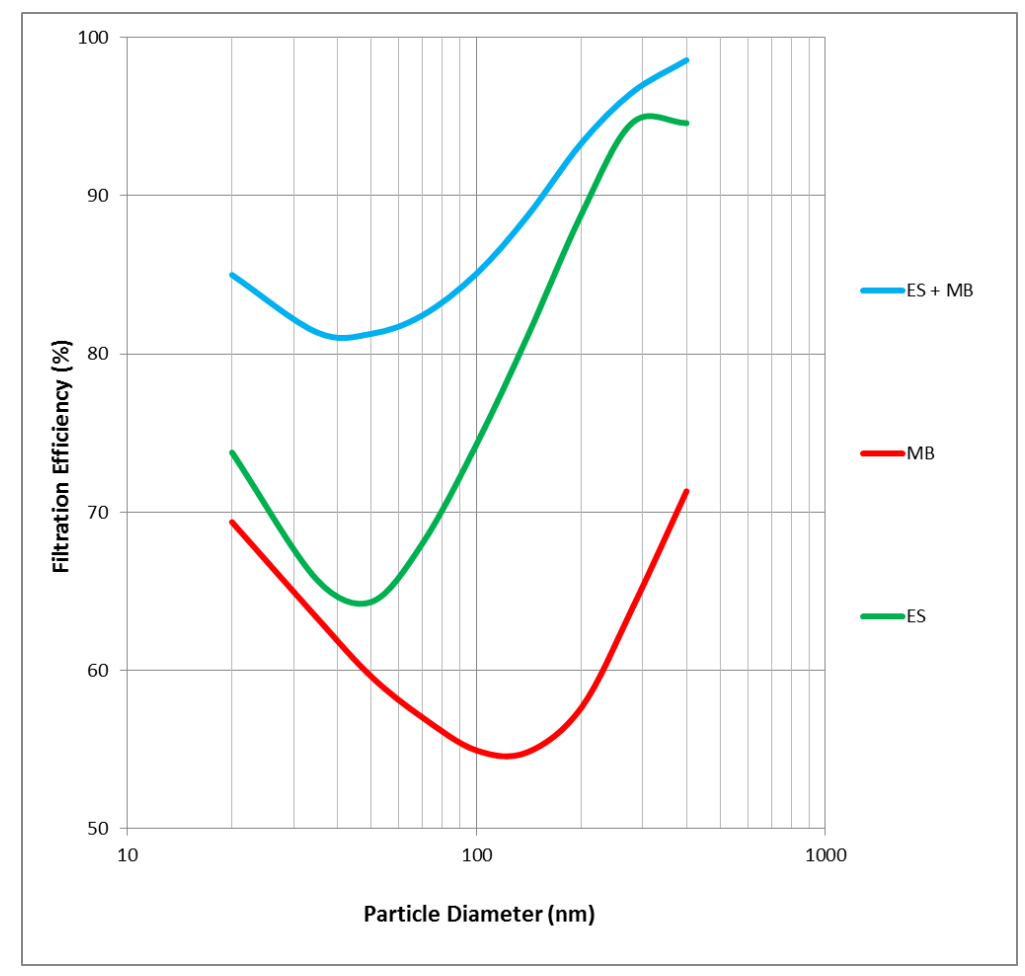

FIGURE 6. Experimental data for ES, MB and ES+MB filtration materials at face velocity $48.3 \mathrm{~cm} . \mathrm{s}^{-1}$.

\section{CONCLUSIONS}

The work presents experimental results and model predictions of filtration efficiencies for ES nanostructured, MB microstructured materials and their combination. Application of nanofiber layer into MB air filtration materials can ensure very high filtration efficiencies for ultrafine particles separation. In comparison of ES and MB filters, the same filtration efficiency can be reached with more than 100 times less polymeric mass in case of application nanofibers. It can be also anticipated that application of nanofibers in filtration materials guarantees higher constancy of air filter material properties because of lower dependence on gradual discharging of MB material.

\section{ACKNOWLEDGMENTS}

This work has been supported by the grants of Czech Ministry of Industry and Trade No. FR-TI1/053 and Technology Agency of the Czech Republic No. TA01010356. Martin Zatloukal wishes to acknowledge Operational Program Research and Development for Innovations co-funded by the European Regional Development Fund (ERDF) and national budget of Czech Republic, within the framework of project Centre of Polymer Systems (reg. number: CZ.1.05/2.1.00/03.0111) for the support.

\section{REFERENCES}

1. D. Kimmer, P. Slobodian, D. Petras, M. Zatloukal, R. Olejnik and P. Saha, J. App. Polym. Sci. 111, 2711-2714 (2009).

2. D. Kimmer, M. Zatloukal, D. Petras, I. Vincent, P. Slobodian, AIP Conference Proceedings, 1152, 305-311 (2009).

3. D. Kimmer, I. Vincent, D. Petras, M. Zatloukal, W. Sambaer, H. Salmela and M. Lehtimaki, "Application of nanofibres in filtration processes," in European Conference On Fluid-Particle Separation (October 5th-7th, Lyon, France, 2010). 
4. D. Kimmer, I. Vincent, J. Fenyk, D. Petras, M. Zatloukal, W. Sambaer, V. Zdimal, AIP Conference Proceedings, 1375, 295-311 (2011).

5. D. Kimmer, I. Vincent, J. Fenyk, D. Petras, M. Zatloukal, W. Sambaer and V. Zdimal, "Morphology of nanofiber structures in ultrafine particles filtration" in 11th World Filtration congress \& Exhibition (Graz, Austria, 2012).

6. D. Kimmer, I. Vincent, J. Lev, L. Kalhotka, P. Mikula, R. Korinkova, W. Sambaer, M. Zatloukal, AIP Conference Proceedings, 1526, 316-325 (2013).

7. D. Kimmer, I. Vincent, V. Marcian, J. Blahova and M. Kovarova, "Application of nanofibres in filter media" in European Conference on Fluid-Particle Separation FPS (Lyon, France, 2014), p. 25-26.

8. W. Sambaer, M. Zatloukal and D. Kimmer, Polym. Test. 29, $82-94$ (2010).

9. W. Sambaer, M. Zatloukal and D. Kimmer, Chem. Eng. Sci. 66, 613-623 (2011).

10. W. Sambaer, M. Zatloukal, D. Kimmer, Chem. Eng. Sci. 82, 299-311 (2012). 
AIP Conference Proceedings is copyrighted by AIP Publishing LLC (AIP). Reuse of AIP content is subject to the terms at: http://scitation.aip.org/termsconditions. For more information, see http://publishing.aip.org/authors/rights-and-permissions. 